\title{
Fracture Mechanism of Interpenetrating Iron-Tricalcium Phosphate Composite
}

\author{
Miroslava Horynová ${ }^{1, a}$, Mariano Casas-Luna ${ }^{1, b}$, Edgar B. Montufar $^{1, c}$, \\ Sebastian Diaz-de-la-Torre ${ }^{2, d}$, Ladislav Celko ${ }^{1, e}$, Lenka Klakurková ${ }^{1}$, \\ Guillermo Diéguez-Trejo ${ }^{2}$, Karel Dvorak ${ }^{3}$, Tomas Zikmund ${ }^{1}$, Jozef Kaiser ${ }^{1, f}$ \\ ${ }^{1}$ CEITEC - Central European Institute of Technology, Brno University of Technology, \\ Brno, Czech Republic \\ ${ }^{2}$ CIITEC - Centro de Investigación e Innovación Tecnológica, Instituto Politécnico Nacional, \\ México \\ ${ }^{3}$ Faculty of Civil Engineering, Brno University of Technology, Brno, Czech Republic \\ amiroslava.horynova@ceitec.vutbr.cz, ${ }^{\mathrm{b}}$ mariano.casasluna@ceitec.vutbr.cz, \\ ceb.montufar@ceitec.vutbr.cz, ${ }^{\mathrm{d}}$ sediazt@yahoo.com.mx, ${ }^{\mathrm{e}}$ ladislav.celko@ceitec.vutbr.cz, \\ jozef.kaiser@ceitec.vutbr.cz
}

Keywords: fracture, composite, calcium phosphate, iron, mechanical testing, micro-tomography.

\begin{abstract}
The usage of iron alloys for bone fractures treatment has been limited due to its high density and elastic modulus, as compared to bone. In contrast, the use of tricalcium phosphate (TCP), a ceramic that promotes bone healing, is mostly limited by its brittle nature. In the present work the fracture mechanism of a novel iron-TCP interpenetrated composite fabricated by spark plasma sintering was studied. Specimens were subjected to a diametral tensile-strength-test. The work of fracture was determined by indirect tensile loading conditions using the diametral tensile strength test. The results revealed that iron has a clear toughening effect on the microstructure of tricalcium phosphate specimens consolidated by spark plasma sintering. This is a promising result to overcome the limited usage of tricalcium phosphate to treat only non-load bearing bone defects.
\end{abstract}

\section{Introduction}

Recently new type of composite material with promising properties suitable for the fabrication of osteosynthetic devises has been developed. This new material is composed by iron and tricalcium phosphate powders and was consolidated by spark plasma sintering [1]. The rationale behind this formulation is that iron can increase the fracture toughness of tricalcium phosphate without compromising the biocompatibility of this ceramic. This work was focused to determine the work of fracture of this new composite to validate the former hypothesis.

The diametral tensile-strength-test was applied to determine the work of fracture of the composite under indirect tensile conditions [2,3]. This method has the advantage of being applied to geometrically simple shape samples, which can be easily fabricated by spark plasma sintering.

\section{Materials and methods}

Tricalcium phosphate powder was prepared by solid state reaction between a stoichiometric mixture of $\mathrm{CaCO}_{3}$ (Sigma-Aldrich $\mathrm{C} 4830$ ) and $\mathrm{CaHPO}_{4}$ (Merck 102304) at $1100{ }^{\circ} \mathrm{C}$ according to the following reaction.

$$
\mathrm{CaCO}_{3}+2 \mathrm{CaHPO}_{4} \rightarrow \mathrm{Ca}_{3}\left(\mathrm{PO}_{4}\right)_{2}+\mathrm{CO}_{2}+\mathrm{H}_{2} \mathrm{O}
$$

Afterwards, the sintered block was milled (Fritsch Pulverisete 6) in isopropanol at $400 \mathrm{rpm}$ using agate jar and balls ( 20 balls of $20 \mathrm{~mm}$ in diameter). Tricalcium phosphate powder was mixed with different volumetric amounts (between 0 and $50 \%$ ) of iron powder (Applied Carbon Nano 
Technologies). The mixtures were homogenized and then consolidated at $1000{ }^{\circ} \mathrm{C}$ by spark plasma sintering (Dr. Sinter 1050 system) applying a direct current of $600 \mathrm{~A}$ at $3 \mathrm{~V}$, in on-off cycles of 12 and $2 \mathrm{~ms}$ (heating rate of $150{ }^{\circ} \mathrm{C} / \mathrm{min}$ ). Samples $(12 \mathrm{~mm}$ in diameter and $6 \mathrm{~mm}$ thickness) were sintered for 10 min applying a constant uniaxial compaction load of $35 \mathrm{MPa}$. The $\mu \mathrm{CT}$ analysis was conducted using the GE phoenix $v \mid$ tome $\mid x$ L 240 system equipped with a $180 \mathrm{kV} / 20 \mathrm{~W}$ maximum power nanofocus X-ray tube and high contrast flat panel detector DXR250.The skeletal densities of the samples were determined by helium pycnometry (AccuPyc II 1340, Micromeritics).

Diametral tensile-strength-test was performed in a TIRA test 2850S universal testing machine, using actuator velocity of $1 \mathrm{~mm} / \mathrm{min}$ until fracture. At least 4 samples of each composition were used in order to define possible measurement errors. The work of fracture $\left(\gamma_{w o f}\right)$ was obtained from the area below of the obtained load $P$ versus actuator displacement $d$ curves, divided by the total projected surface area $A$ of the two obtained fracture surfaces, Eq. 2.

$$
\gamma_{\text {wof }}=\frac{\int_{0}^{\mathrm{d}_{\text {fracture }} P d \mathrm{~d}}}{2 \mathrm{~A}} .
$$

The area below the $P$ versus $d$ curve was numerically integrated applying the trapezoidal rule.

$$
\int_{0}^{\mathrm{d}_{\text {fracture }}} P d \mathrm{~d} \approx \frac{\mathrm{d}_{\text {fracture }}}{2 N} \sum_{i=1}^{N}\left(P\left(\mathrm{~d}_{i+1}\right)+P\left(\mathrm{~d}_{i}\right)\right),
$$

where $\mathrm{d}_{\text {fracture }}$ is the actuator displacement when fracture occurred.

The appearance of the fracture surfaces was observed by scanning electron microscope (TESCAN Lyra3) on samples previously coated with thin carbon layer to prevent charging during observation.

\section{Results and discussion}

Samples were systematically fabricated by spark plasma sintering method. Samples prepared with no iron addition presented the typical white color of calcium phosphate ceramics, while samples containing iron presented dark grey metallic aspect. X-ray computed micro-tomography showed that the two components form a continuous three-dimensional network in the material (Figure 1). The samples developed a good degree of densification as their surfaces presented bright appearance. Furthermore, the measured density of the samples was above $95 \%$ of their theoretical density, determined by considering the volumetric fraction of their components.

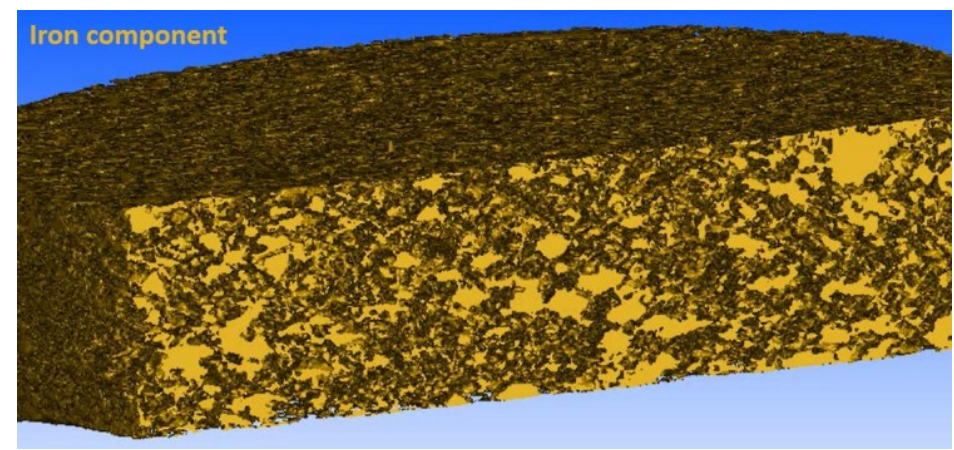

Figure 1. Tomographic reconstruction, showing an internal plane in the iron-TCP composite. The image only shows iron position, while the TCP was virtually removed for clarity.

All samples disclosed brittle fracture behavior during the diametral tensile-strength-test. Just as shown in Fig. 2, the fracture propagated longitudinally through the diameter of the specimens, between the points where the load was applied. Representative scanning electron microscope 
images of the fracture surfaces are included in Fig. 3. Both, pure tricalcium phosphate and the irontricalcium phosphate composites, presented brittle fracture surface, i.e. without evidence of plastic deformation. Besides, iron particles were not detached from the surface, suggesting good interphase adhesion. While tested by means of compression test, iron exhibited ductile fracture while intergranular decohesion was observed for TCP areas.

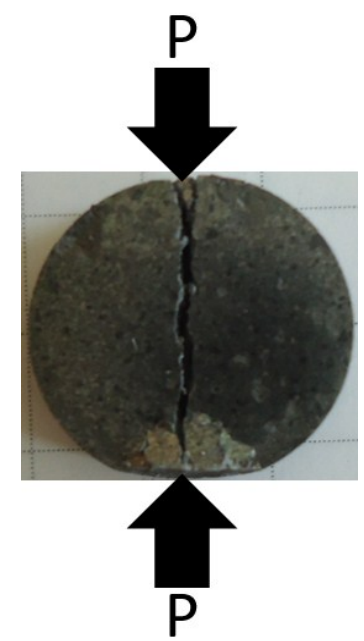

Figure 2. Representative image of the fracture of the spark plasma sintering samples, after the diametral tensile-strength-test.

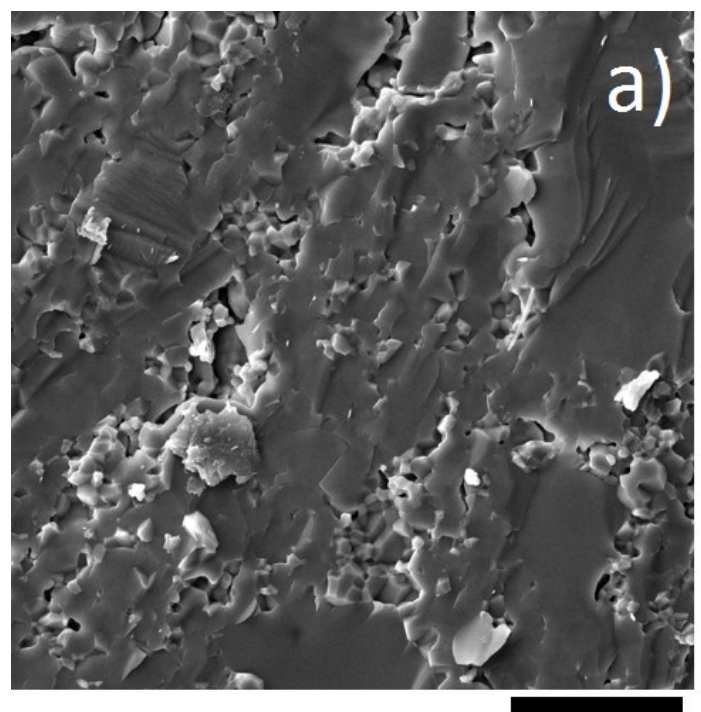

$10 \mu \mathrm{m}$

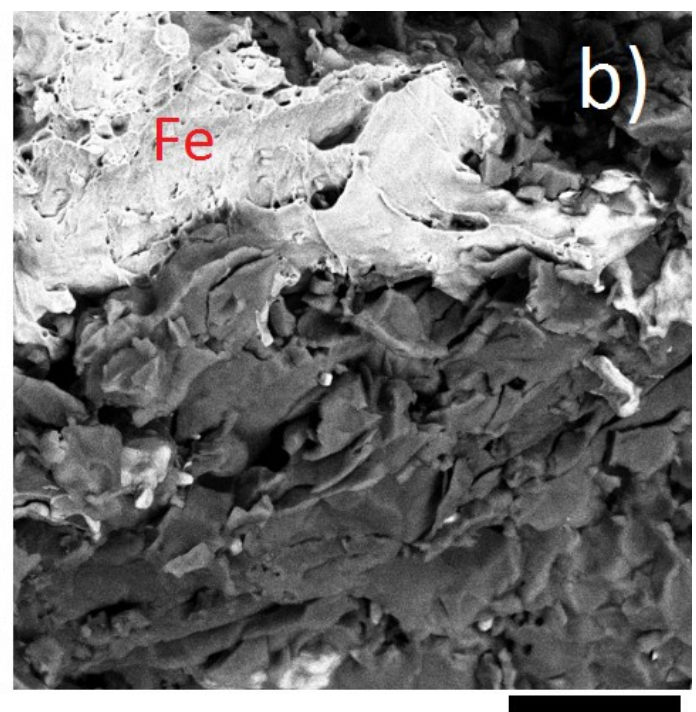

$10 \mu \mathrm{m}$

Figure 3. Representative scanning electron microscope images of the fracture surface of a) pure tricalcium phosphate and b) 50 volume $\%$ iron - tricalcium phosphate composite, consolidated by spark plasma sintering. Fe indicates the position of iron in the composite fracture surface.

Fig. 4 shows the $\gamma_{\text {wof }}$ determined for the studied samples. Results show a positive correlation between $\gamma_{w o f}$ and iron content. The linear regression indicates a correlation factor $R^{2}$ of 0.96 . This fact suggests that the incorporation of iron promotes the toughening of the microstructure of tricalcium phosphate consolidated by spark plasma sintering. The possible toughening mechanisms include grain bridging, crack deflection or microcracking [4]. Although the specific toughening mechanism was not yet determined, the improved fracture toughness of tricalcium phosphate has relevant implications. For example, the application of tricalcium phosphate to treat bone defects is limited by its brittle mechanical behavior [5], therefore, the addition of iron, a metal well tolerated by the human body [6], can extend the use of tricalcium phosphate to load bearing conditions. Nonetheless, further research is required to proof the functionality of this composite material for possible clinical applications. 


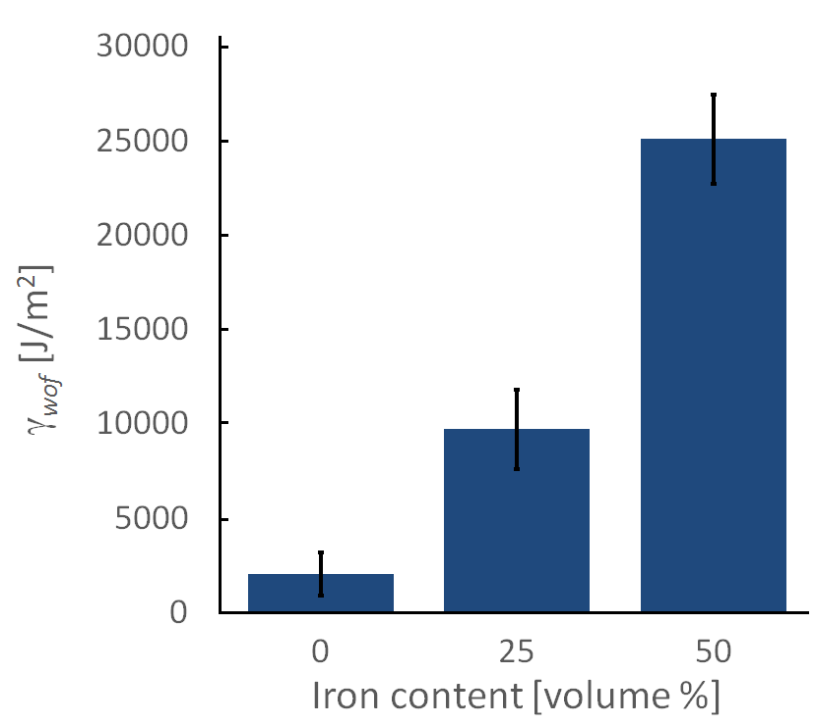

Figure 4 . The work of fracture $\left(\gamma_{w o f}\right)$ of the composites plotted as function of iron content.

\section{Conclusion}

The incorporation of iron in tricalcium phosphate ceramic specimens, consolidated by the spark plasma sintering, considerably increases the toughness, as deduced from the higher energy required to facture these composites. Nonetheless, at the studied chemical compositions, the brittle nature of tricalcium phosphate still dominates the fracture behavior of the composites.

\section{Acknowledgements}

This work is part of the project 5SA14857, which has acquired the financial contribution from the EU Framework Program for Research and Innovation Horizon 2020, within the scope of the Marie Sklodowska-Curie Actions, co-financed by the South Moravian Region according to the Grant Agreement no. 665860. The research is further co-financed by project CEITEC 2020 (LQ1601) with financial support from the Ministry of Education, Youth and Sports of the Czech Republic under the National Sustainability Program II. MCL acknowledges Brno Ph. D. Talent scholarship founded by the Brno City Municipality. SDT acknowledges to CONACYT-SNI (P.1777000).

\section{References}

[1] E.B. Montufar, M. Horynová, M. Casas-Luna, S. Diaz-de-la-Torre, L. Celko, L. Klakurková, Z. Spotz, G. Diéguez-Trejo, Z. Fohlerová, K. Dvorak, T. Zikmund and J. Kaiser: JOM Vol. 68 (2016), p. 1134.

[2] R. Berenbaum and I. Brodie: Br. J. Appl. Phys. Vol. 10 (1959), p. 281.

[3] A.T. Procopio, A. Zavaliangos, and J.C. Cunningham: J. Mater. Sci. Vol. 38 (2003), p. 3629.

[4] R.W. Steinbrech: J. Euro. Cer. Soc. Vol. 10, (1992), p. 131.

[5] S.V. Dorozhkin: Biomaterials Vol. 31 (2010), p. 1465.

[6] A. Francis, Y. Yang, S. Virtanen and A. R. Boccaccini: J. Mater. Sci.: Mater. Med. Vol. 26 (2015), p. 138. 